\title{
Design of aluminium alloy stocky hollow sections subjected to concentrated transverse loads
}

DOI:

10.1016/j.tws.2017.12.015

\section{Document Version}

Accepted author manuscript

Link to publication record in Manchester Research Explorer

\section{Citation for published version (APA):}

Su, M., \& Young, B. (2018). Design of aluminium alloy stocky hollow sections subjected to concentrated transverse loads. Thin-Walled Structures, 124, 546-557. https://doi.org/10.1016/j.tws.2017.12.015

\section{Published in:}

Thin-Walled Structures

\section{Citing this paper}

Please note that where the full-text provided on Manchester Research Explorer is the Author Accepted Manuscript or Proof version this may differ from the final Published version. If citing, it is advised that you check and use the publisher's definitive version.

\section{General rights}

Copyright and moral rights for the publications made accessible in the Research Explorer are retained by the authors and/or other copyright owners and it is a condition of accessing publications that users recognise and abide by the legal requirements associated with these rights.

\section{Takedown policy}

If you believe that this document breaches copyright please refer to the University of Manchester's Takedown Procedures [http://man.ac.uk/04Y6Bo] or contact uml.scholarlycommunications@manchester.ac.uk providing relevant details, so we can investigate your claim.

\section{OPEN ACCESS}




\title{
Design of aluminium alloy stocky hollow sections subjected to concentrated transverse loads
}

\author{
Mei-Ni Su ${ }^{1}$ and Ben Young ${ }^{2}$
}

\begin{abstract}
Web crippling is a phenomenon where section webs cripple due to a concentrated force. This phenomenon could be caused by web buckling for slender sections or by web bearing/yielding for stocky sections. The aim of this study is to investigate the web bearing design rules for relatively stocky sections. Experimental tests and numerical modelling results on aluminium alloy square and rectangular hollow sections (SHS/RHS) subjected to web bearing are presented. The tests were conducted under four loading conditions: end-two-flange (ETF), interior-two-flange (ITF), end-one-flange (EOF), and interior-one-flange (IOF). Two different bearing lengths, $50 \mathrm{~mm}$ and $90 \mathrm{~mm}$, were investigated. The test specimens were fabricated by extrusion using 6063-T5 and 6061-T6 heat-treated aluminium alloys. Web slenderness values (i.e. the width-to-thickness ratio $h / t$ ) ranging from 2.8 to 28.0 have been considered. Non-linear finite element (FE) models were developed and validated against the test strengths and specimen failure modes. Upon validation, the FE models were used to perform a parametric study in order to supplement the experimental work. A total of 138 web bearing data consisting of 34 test results and 104 numerical results were generated in this study. In the ETF and ITF loading conditions, all specimens failed by material yielding at the webs. For the EOF and IOF loading conditions, specimens failed by flexural failure, interaction of web bearing and bending effects or material fracture at the tension flanges. The generated data is used to assess the web bearing design equations in the existing design codes as well as to propose new design rules. The new design rules for ETF and ITF loading conditions are proposed with the consideration of strain hardening effects. Further analyses have been carried out to show the newly proposed design rules are not only accurate and consistent, but also safe and reliable.
\end{abstract}


KEY WORDS: Aluminium alloys; Concentrated loads; Experimental investigation; Finite element; Reliability analyses; Square and rectangular hollow sections; Web bearing

${ }^{1}$ Lecturer, School of Mechanical, Aerospace and Civil Engineering, University of Manchester, Manchester, M1 3NJ, UK

${ }^{2}$ Professor, Dept. of Civil Engineering, The University of Hong Kong, Pokfulam Road, Hong Kong. E-mail: young@hku.hk 


\section{Introduction}

Web crippling is a form of localized failure that occurs at points under concentrated transverse loading of thin-walled structural members and is one of the common local failure modes [1]. Web crippling can be classified in a more detailed way as web buckling for relatively slender sections and web bearing for relatively stocky sections. Up to now, the majority of existing studies were focused on web buckling design of relatively slender sections, including experimental investigation [2-6] and numerical simulation $[3,7,8]$. Moreover, most of the available test results were on stainless steel members [9-13]. Though stainless steel and aluminium alloys are both metallic materials with similar continuous stress-strain curves without a clear yielding point, for efficient and economical structural design, it is important to recognise the key characteristics of aluminium alloys, such as the nonlinear material stress-strain curves with significant strain hardening and reasonable ductility [14]. The present study investigates the performance of aluminium alloy sections subjected to web bearing.

Though web buckling and web bearing are two different failure mechanisms, some of the international design specifications such as the Aluminum Design Manual (AA) [15] and the Australian/New Zealand Standards - Aluminum Structures (AS/NZS) [16] provide only one series of equations for the web design. Other specifications such as Eurocode 9 - Design of Aluminium Structures (EC9) [17], the Specification for Structural Steel Buildings (AISC) [18], the Australian Standard - Steel Structures (AS4100) [19] and Eurocode 3 - Design of Steel Structures EN 1993-1-3 (EC3) [20] 
do provide corresponding design rules for different failure mode. These existing design rules for the web bearing strength were all derived through semi-empirical and theoretical bases, and are based on experimental investigation conducted by researchers from the 1940s onwards, such as Winter and Pian [21], Zetlin [22], Hetrakul and Yu [23], Young and Hancock [1] and so on.

Aluminium alloy tubular sections are becoming increasing popular in structural applications, especially for roofing system, building facade, moving bridges and structures in corrosive environment. The webs of tubular members may be subjected to concentrated forces when used in a floor system [5]. Two loading conditions are considered in the specifications: interior loading and end loading. The AISI Specification [24] specifies that when the distance from the edge of the bearing to the end of the member is less than or equal to 1.5 times the clear depth of the web, it is classified as end loading, otherwise it is classified as interior loading. When considering the concentrated load acting on one flange or two flanges, four loading conditions of prime interest are classified: end-one-flange (EOF), interior-one-flange (IOF), end-two-flange (ETF), and interior-two-flange (ITF). Some design codes treat the one-flange and two-flange loading conditions as being the same.

In this paper, aluminium alloy square and rectangular hollow sections (SHS/RHS) were tested under the four loading conditions of EOF, ETF, IOF, and ITF. The concentrated loads were applied by means of bearing plates of two bearing lengths, 50 
$\mathrm{mm}$ and $90 \mathrm{~mm}$. The test specimens were extruded by normal strength (6063-T5) and high-strength (6061-T6) aluminium alloys. Finite element (FE) models were developed using ABAQUS version 6.12 [25] and validated against the test results generated in this study. The validated models were then used to conduct a parametric study and 104 additional numerical results were generated. Since this research focuses on web bearing design, only the specimens failed by web bearing are included. The combined experimental and numerical data, with slenderness values $(h / t)$ of 2.8 to 28.0, were used to assess the web bearing design rules in the aforementioned international specifications. Using the results, a series of more accurate design equations for two-flange loading configurations were proposed, and assessed by reliability analyses.

\section{Experimental investigation}

A series of tests on aluminium alloy square and rectangular hollow sections (SHS/RHS) subjected to web bearing were performed at the structural laboratory at The University of Hong Kong.

\subsection{Test specimens}

The test specimens consisted of different cross-section dimensions with nominal heights of the webs ranging from $50 \mathrm{~mm}$ to $120 \mathrm{~mm}$. Tables $1-4$ show the measured test specimen dimensions and material properties. Fig. 1 illustrates the section dimensions, where $B$ is the flange width, $H$ is the web width, $h$ is the flat width of web, $t$ is the thickness and $L$ is the stub column length. As for the listed material properties, 
$E$ is the Young's modulus, $f_{y}$ is the material yield stress (taken as the $0.2 \%$ proof stress), $f_{u}$ is the material ultimate stress, $\varepsilon_{u}$ is the strain at ultimate stress and $\varepsilon_{f}$ is the strain at fracture. The web slenderness $h / t$ ratios ranged from 2.8 to 11.5 , which belong to the class 1 proportion [17]. The specimen length $L$ was determined according to the AS/NZS 4600 [26] and the AISI [24] specifications. The clear distance between opposed loads was set to be 1.5 times the overall depth of the web.

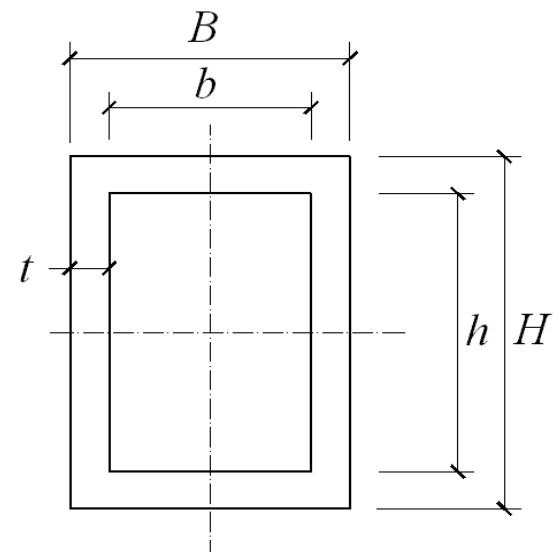

Fig. 1. Definition of symbols for SHS/ RHS with all elements of thickness $t$

\subsection{Specimen labelling}

In Tables 1-4, the specimens are labelled such that the specimen materials, cross-section dimensions, the loading condition, and the length of the bearing plates can be identified from the label. For example, the label "H50 $\times 90 \times 10.5-E T F-N 50-R$ " defines the following specimen:

- The first letter "H" refers to high strength aluminium alloy 6061-T6, while "N" refers to normal strength aluminium alloy 6063-T5

- The nominal cross-section has dimensions of width $(50 \mathrm{~mm}) \times$ height $(90 \mathrm{~mm}) \times$ thickness (10.5 mm); 
- The next three letters indicate the loading condition that was used in the tests; that is a loading condition of either end-one-flange (EOF), interior-one-flange (IOF), end-two-flange (ETF), or interior-two-flange (ITF).

- The notation "N50" indicates the length of bearing, here it is $50 \mathrm{~mm}$.

- If a test was repeated, a letter " $\mathrm{R}$ " is shown in the label.

\subsection{Dimensions and material properties}

The specimens were extruded from two commonly used aluminium alloys, normal strength aluminium alloy, 6063-T5, and high strength aluminium alloy, 6061-T6. The material properties of the test specimens were determined by tensile coupon tests. Coupon tests conformed to the Australian standard AS 1391 [27] and the ASTM standard [28]. The static load was obtained by pausing the applied straining for one minute near the $0.2 \%$ tensile proof stress and the ultimate tensile strength.

Table 1. Measured specimen dimensions and material properties for the ETF loading condition

\begin{tabular}{|c|c|c|c|c|c|c|c|c|c|c|}
\hline Specimen & $\begin{array}{c}B \\
(\mathrm{~mm})\end{array}$ & $\begin{array}{c}H \\
(\mathrm{~mm})\end{array}$ & $\begin{array}{c}t \\
(\mathrm{~mm})\end{array}$ & $\begin{array}{c}L \\
(\mathrm{~mm})\end{array}$ & $h / t$ & $\begin{array}{c}E \\
(\mathrm{GPa})\end{array}$ & $\begin{array}{c}f_{0.2} \\
(\mathrm{MPa})\end{array}$ & $\begin{array}{c}f_{u} \\
(\mathrm{MPa})\end{array}$ & $\begin{array}{c}\varepsilon_{u} \\
(\%)\end{array}$ & $\begin{array}{c}\varepsilon_{f} \\
(\%)\end{array}$ \\
\hline H95×50×10.5-ETF-N50 & 94.7 & 49.6 & 10.36 & 125 & 2.79 & 70 & 179.2 & 220.5 & 8.1 & 14.1 \\
\hline H50×95×10.5-ETF-N50 & 49.7 & 94.7 & 10.35 & 196 & 7.14 & 69 & 192.0 & 232.2 & 7.7 & 10.9 \\
\hline H50×95×10.5-ETF-N50-R & 49.7 & 94.7 & 10.38 & 193 & 7.13 & 69 & 192.0 & 232.3 & 7.7 & 10.9 \\
\hline N120×70×10.5-ETF-N50 & 119.7 & 69.8 & 10.40 & 155 & 4.72 & 71 & 139.1 & 194.0 & 6.6 & 14.1 \\
\hline N70 $\times 120 \times 10.5-E T F-N 50$ & 69.9 & 119.9 & 10.41 & 230 & 9.51 & 71 & 139.1 & 194.0 & 6.6 & 14.1 \\
\hline N120×120×9.0-ETF-N50 & 119.8 & 119.8 & 8.88 & 231 & 11.50 & 71 & 182.9 & 224.8 & 9.7 & 14.3 \\
\hline H95×50×10.5-ETF-N90 & 94.7 & 49.7 & 10.34 & 166 & 2.80 & 70 & 179.2 & 220.5 & 8.1 & 14.1 \\
\hline H50×95×10.5-ETF-N90 & 49.7 & 94.8 & 10.35 & 234 & 7.15 & 70 & 232.0 & 244.5 & 4.3 & 7.9 \\
\hline H120×70×10.5-ETF-N90 & 119.8 & 69.8 & 10.38 & 194 & 4.73 & 69 & 225.7 & 238.3 & 7.9 & 10.1 \\
\hline $\mathrm{H} 70 \times 120 \times 10.5$-ETF-N90 & 69.9 & 119.9 & 10.43 & 272 & 9.50 & 69 & 225.7 & 238.3 & 7.9 & 10.1 \\
\hline N120×120×9.0-ETF-N90 & 119.8 & 119.9 & 8.90 & 270 & 11.47 & 71 & 182.9 & 224.8 & 9.7 & 14.3 \\
\hline
\end{tabular}


Table 2. Measured specimen dimensions and material properties for the ITF loading condition

\begin{tabular}{|c|c|c|c|c|c|c|c|c|c|c|}
\hline Specimen & $\begin{array}{c}B \\
(\mathrm{~mm})\end{array}$ & $\begin{array}{c}H \\
(\mathrm{~mm})\end{array}$ & $\begin{array}{c}t \\
(\mathrm{~mm})\end{array}$ & $\begin{array}{c}L \\
(\mathrm{~mm})\end{array}$ & $h / t$ & $\begin{array}{c}E \\
(\mathrm{GPa})\end{array}$ & $\begin{array}{c}f_{0.2} \\
(\mathrm{MPa})\end{array}$ & $\begin{array}{c}f_{u} \\
(\mathrm{MPa})\end{array}$ & $\begin{array}{c}\varepsilon_{u} \\
(\%)\end{array}$ & $\begin{array}{c}\varepsilon_{f} \\
(\%)\end{array}$ \\
\hline H95 $\times 50 \times 10.5-$ ITF-N50 & 94.7 & 49.6 & 10.33 & 200 & 2.80 & 70 & 179.2 & 220.5 & 8.1 & 14.1 \\
\hline H50×95×10.5-ITF-N50 & 49.7 & 94.8 & 10.35 & 335 & 7.16 & 70 & 179.2 & 220.5 & 8.1 & 14.1 \\
\hline N120×70×10.5-ITF-N50 & 119.8 & 69.9 & 10.38 & 261 & 4.73 & 71 & 139.1 & 194.0 & 6.6 & 14.1 \\
\hline N70 $\times 120 \times 10.5-\mathrm{ITF}-\mathrm{N} 50$ & 69.9 & 119.9 & 10.36 & 412 & 9.57 & 71 & 139.1 & 194.0 & 6.6 & 14.1 \\
\hline N120×120×9.0-ITF-N50 & 119.9 & 119.9 & 8.89 & 409 & 11.49 & 71 & 182.9 & 224.8 & 9.7 & 14.3 \\
\hline H95×50×10.5-ITF-N90 & 94.8 & 49.7 & 10.34 & 241 & 2.81 & 70 & 179.2 & 220.5 & 8.1 & 14.1 \\
\hline H50×95×10.5-ITF-N90 & 49.7 & 94.7 & 10.37 & 376 & 7.14 & 70 & 179.2 & 220.5 & 8.1 & 14.1 \\
\hline H50×95×10.5-ITF-N90-R & 49.7 & 94.7 & 10.36 & 377 & 7.14 & 69 & 163.6 & 210.9 & 7.3 & 13.6 \\
\hline N120×70×10.5-ITF-N90 & 119.9 & 69.9 & 10.39 & 302 & 4.73 & 71 & 139.1 & 194.0 & 6.6 & 14.1 \\
\hline N70 $\times 120 \times 10.5-$ ITF-N90 & 69.9 & 119.9 & 10.45 & 449 & 9.48 & 71 & 139.1 & 194.0 & 6.6 & 14.1 \\
\hline N120×120×9.0-ITF-N90 & 119.9 & 119.8 & 8.89 & 450 & 11.48 & 71 & 182.9 & 224.8 & 9.7 & 14.3 \\
\hline
\end{tabular}

Table 3. Measured specimen dimensions and material properties for the EOF loading condition

\begin{tabular}{|c|c|c|c|c|c|c|c|c|c|c|}
\hline Specimen & $\begin{array}{c}B \\
(\mathrm{~mm})\end{array}$ & $\begin{array}{c}H \\
(\mathrm{~mm})\end{array}$ & $\begin{array}{c}t \\
(\mathrm{~mm})\end{array}$ & $\begin{array}{c}L \\
(\mathrm{~mm})\end{array}$ & $h / t$ & $\begin{array}{c}E \\
(\mathrm{GPa})\end{array}$ & $\begin{array}{c}f_{0.2} \\
(\mathrm{MPa})\end{array}$ & $\begin{array}{c}f_{u} \\
(\mathrm{MPa})\end{array}$ & $\begin{array}{c}\varepsilon_{u} \\
(\%)\end{array}$ & $\begin{array}{c}\varepsilon_{f} \\
(\%)\end{array}$ \\
\hline H95×50×10.5-EOF-N50 & 94.7 & 49.6 & 10.29 & 341 & 2.82 & 70 & 179.2 & 220.5 & 8.1 & 14.1 \\
\hline H50×95×10.5-EOF-N50 & 49.7 & 94.8 & 10.31 & 476 & 7.20 & 70 & 179.2 & 220.5 & 8.1 & 14.1 \\
\hline H50×95×10.5-EOF-N50-R & 49.7 & 94.8 & 10.29 & 477 & 7.21 & 70 & 179.2 & 220.5 & 8.1 & 14.1 \\
\hline $\mathrm{N} 120 \times 70 \times 10.5-\mathrm{EOF}-\mathrm{N} 50$ & 119.8 & 69.9 & 10.31 & 401 & 4.78 & 71 & 139.1 & 194.0 & 6.6 & 14.1 \\
\hline $\mathrm{N} 70 \times 120 \times 10.5-\mathrm{EOF}-\mathrm{N} 50$ & 69.9 & 119.9 & 10.26 & 554 & 9.69 & 71 & 139.1 & 194.0 & 6.6 & 14.1 \\
\hline N120×120×9.0-EOF-N50 & 119.8 & 119.9 & 26.82 & 550 & 2.47 & 71 & 182.9 & 224.8 & 9.7 & 14.3 \\
\hline
\end{tabular}

Table 4. Measured specimen dimensions and material properties for the IOF loading condition

\begin{tabular}{|c|c|c|c|c|c|c|c|c|c|c|}
\hline Specimen & $\begin{array}{c}B \\
(\mathrm{~mm})\end{array}$ & $\begin{array}{c}H \\
(\mathrm{~mm})\end{array}$ & $t(\mathrm{~mm})$ & $\begin{array}{c}L \\
(\mathrm{~mm})\end{array}$ & $h / t$ & $\begin{array}{c}E \\
(\mathrm{GPa})\end{array}$ & $\begin{array}{c}f_{0.2} \\
(\mathrm{MPa})\end{array}$ & $\begin{array}{c}f_{u} \\
(\mathrm{MPa})\end{array}$ & $\begin{array}{c}\varepsilon_{u} \\
(\%)\end{array}$ & $\begin{array}{c}\varepsilon_{f} \\
(\%)\end{array}$ \\
\hline H95×50×10.5-IOF-N50 & 94.7 & 49.7 & 10.35 & 301 & 2.80 & 70 & 179.2 & 220.5 & 8.1 & 14.1 \\
\hline H50×95×10.5-IOF-N50 & 49.7 & 94.7 & 10.36 & 436 & 7.14 & 69 & 163.6 & 210.9 & 7.3 & 13.6 \\
\hline H50×95×10.5-IOF-N50-R & 49.8 & 94.9 & 10.36 & 436 & 7.16 & 69 & 163.6 & 210.9 & 7.3 & 13.6 \\
\hline N120×70×10.5-IOF-N50 & 119.9 & 69.9 & 10.39 & 360 & 4.73 & 71 & 139.1 & 194.0 & 6.6 & 14.1 \\
\hline N70×120×10.5-IOF-N50 & 69.9 & 119.9 & 10.31 & 508 & 9.63 & 71 & 139.1 & 194.0 & 6.6 & 14.1 \\
\hline N120×120×9.0-IOF-N50 & 120.0 & 120.0 & 8.91 & 511 & 11.46 & 69 & 180.6 & 228.0 & 8.9 & 14.0 \\
\hline
\end{tabular}

\subsection{Loading conditions and test rig}

The box section specimens were tested using the four loading conditions according to the AISI Specification [24] and the Australian/New Zealand Standard AS/NZS4600 [26]. These loading conditions were end-two-flange (ETF), end-one-flange (EOF), 
interior-two-flange (ITF) and interior-one-flange (IOF), as shown in Li and Young [29]. The loads were applied by means of steel bearing plates. The thickness of the bearing plate was $50 \mathrm{~mm}$, and two bearing lengths of $50 \mathrm{~mm}$ and $90 \mathrm{~mm}$ were employed. All the bearing plates were designed to act across the full flange widths of the hollow sections. The flanges of the specimens were not fastened to the bearing plates during testing. A servo-controlled hydraulic testing machine was used to apply a vertical transverse force to the test specimens. Displacement control was used to drive the hydraulic actuator at a constant speed of $0.4 \mathrm{~mm} / \mathrm{min}$. The loads and the transducer readings were recorded at 1 second intervals during the tests. In the test set-up, hinge and pin supports were simulated by half rounds and rollers

For the ETF and ITF loading conditions, two identical bearing plates of the same width were positioned at the end or the mid-length of each specimen, respectively. Photographs of the ETF and ITF tests are shown in Figs. 3(a) and 3(b), respectively.

In the EOF loading condition, the defined web bearing failure occurs at the ends due to the concentrated loads. The length of the bearing plate $N$ in the labels refers to the length of the end bearing plates. The mid-span bearing plate is two times larger than the end bearing plates and steel stiffeners were adopted in the mid-span in order to avoid the local buckling at the mid-span. Local failure is more prone to occur at the end webs. The web deformations of the specimens were measured between the top and bottom surfaces of the specimens at both ends. A photograph of the test 
arrangement of EOF loading is shown in Fig. 3(c).

The test under the IOF loading condition is shown in Fig. 3(d). In the IOF configuration, local failure is prone to occur at the interior webs as web bearing with the material yielding due to the concentrated loads. Three bearing plates of the same length $N$ were used so that the stress at the mid-span cross-section is greater than the end cross-section. The measurement of the mid-span web deformation uses a stiff steel plate adhesive to the bottom flange of the specimen, as shown in Fig. 3(d).

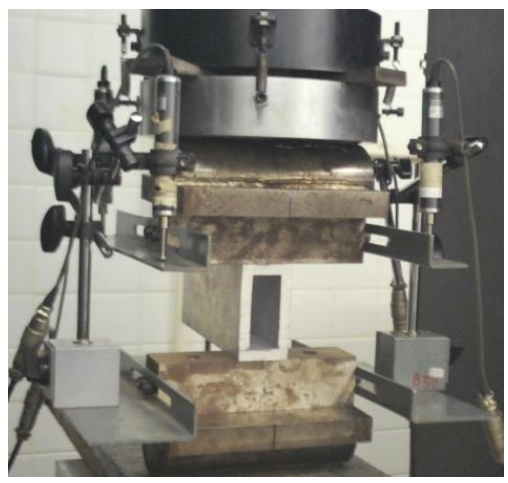

(a) ETF

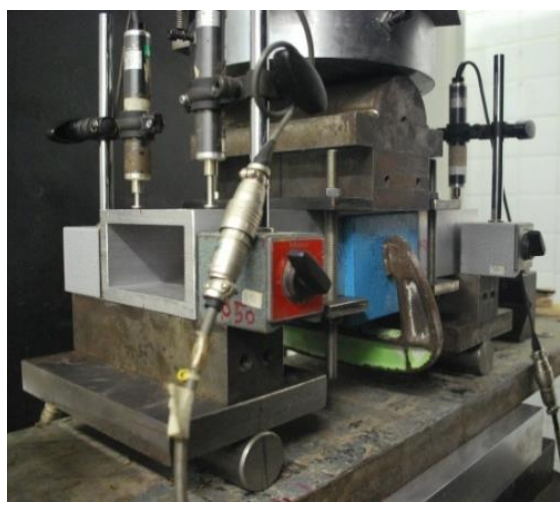

(c) $\mathrm{EOF}$

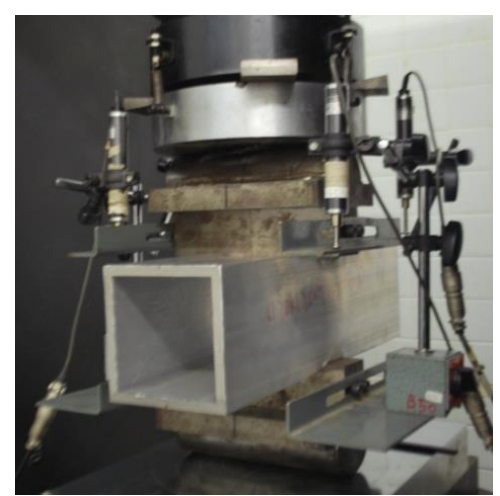

(b) ITF

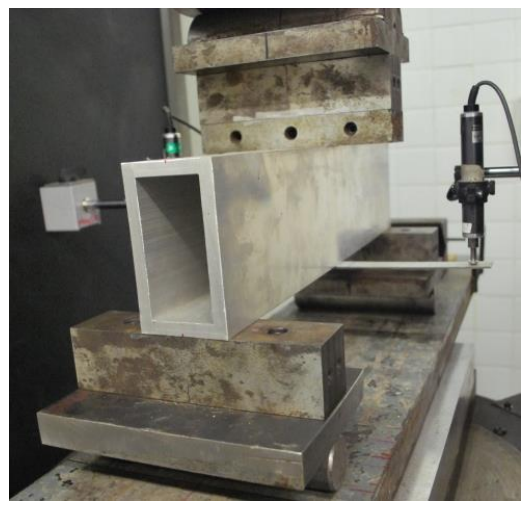

(d) IOF

Fig. 3: Web bearing tests under four loading conditions 


\subsection{Test results}

A total of 11 specimens were tested under the ETF, 11 under the ITF, 6 under the EOF, and 6 under the IOF. The test results for the repeated tests were close to their first test values. Typical curves of applied loads against the measured web deformation are presented in Figs. 7-8 and the summary table of test results are given in Tables 5-8.

Since the research focuses on web design at load concentrated area, failure modes were only determined at specific locations. Specifically, only webs at external locations are considered for ETF and EOF loading conditions, and only webs at the interior locations are considered for ITF and IOF loading conditions. Web buckling was not observed at the ultimate load for all tested specimens. Instead, web bearing (B), flexural failure (F) and tensile material fracture (split) (S) were observed in the tested specimens. In both two-flange loading conditions, ETF and ITF, all specimens failed by material yielding of webs at the load concentrated positions, which is known as web bearing (B). It was seen that the pure web bearing capacities for one-flange loading conditions (EOF and IOF) cannot be obtained since the webs were stocky. In the EOF loading condition, the failure was affected significantly by bending effect. One specimen $(\mathrm{N} 120 \times 120 \times 9.0-\mathrm{EOF}-\mathrm{N} 50)$ failed by fracture at the mid-span, while the other five specimens failed because the mid-span cross-section reached its bending moment capacity, which is flexural failure. In neither of these two situations, the cross-sections or the webs at the beam ends yielded or failed. For the IOF 
condition, the considered cross-section is at the mid-span where specimens failed by primarily by tensile material fracture $(\mathrm{S})$ or flexural failure $(\mathrm{F})$, but some web bearing (B) was also observed. In both EOF and IOF loading conditions, none specimens failed purely by web bearing, which means that the test results for one-flange loading conditions do not reflect the pure web bearing capacities. The failure modes are reported in Tables 5-8.

\section{Finite element modelling}

The finite element program ABAQUS version 6.12 [25] was used to simulate aluminium alloy tubular sections subjected to concentrated transverse loads. The modelling was performed for full cross-sections even though specimens have symmetry in their geometry.

\subsection{Element type and mesh}

The reduced integration four-noded doubly curved shell element (S4R) was employed in the present study to model the continuous beams. The S4R general purpose shell element has six degrees of freedom per node and provides an accurate solution to problems of the nature addressed in this study [30]. The specimen was modelled by deformable extrusion, and the bearing plates were modelled using rigid bodies. A uniform mesh size of $5 \mathrm{~mm} \times 5 \mathrm{~mm}$ was chosen for all specimens and bearing plates. 


\subsection{Boundary condition and modelling method}

The boundary conditions were modelled according to the tests conducted in the laboratory. The movement of the top bearing plate was restrained in the longitudinal direction and in the out-of-plane direction. Compressive loads were applied at the representative point at the top bearing plates. For the ETF and ITF loading conditions, the bottom bearing plates were restrained in all directions. For the EOF and IOF loading conditions, the longitudinal $\mathrm{Z}$ direction of the bottom plates was free to move in order to simulate rollers. The specimens were restrained longitudinally at the mid-span only.

The interfaces between the steel bearing plates and the aluminium alloy specimen were modelled using a contact pair. Hard contact in the normal direction and frictionless condition in the tangential direction were used between the bearing plate (master surface) and the specimen surface (slave surface). The two surfaces were prevented from penetrating into each other, but allowed to separate after contact. Tie interaction was used for the contact edges between the specimens and the bearing plates.

The loading control used in the FE analysis was similar to that used in the tests, where the load was applied by imposing vertical displacement to the solid bearing plates. The Riks procedure with automatic increment sizing, as described in ABAQUS 6.12 [25] was used to allow the post-ultimate path of the modelled specimens to be captured. 


\subsection{Material modelling}

The elastic part of the stress-strain curve was represented by the measured Young's modulus as well as using the Poisson's ratio of 0.33 . For the inelastic part, the material nonlinearity was included in the FE models by specifying set of values of true stress and true plastic strain using the incremental plasticity model. The relationship between the true stress $\sigma_{t r u e}$ and the engineering stress $\sigma$, as well as the true plastic strain $\varepsilon_{\text {true }}^{p l}$ and the engineering strain $\varepsilon$ are given by Eqs. (1) and (2), respectively.

$$
\begin{aligned}
\sigma_{\text {true }} & =\sigma(1+\varepsilon) \\
\varepsilon_{\text {true }}^{p l} & =\ln (1+\varepsilon)-\sigma_{\text {true }} / E
\end{aligned}
$$

where $E$ is the Young's modulus.

\subsection{Validation of the numerical model}

The FE models were validated by the comparison against 34 physical test results from four different loading conditions. The results are shown in Tables 5 - 8. Comparisons can be made between failure modes and load-deformation behaviour.

In the ETF and ITF loading conditions, the only failure mode obtained from finite element models was web bearing, which is consistent with the observations from tests. It is shown that for some specimens, all the webs under the concentrated loads reached the yield stress (see Fig. 4(a)), but for other specimens, only some of the webs (near the load concentrated flanges) reached the yield stress (see Fig. 4(b)). No local 
buckling occurs at the webs. Similarly, for the EOF loading condition, when the specimen reached the ultimate load, no local buckling or material yielding was observed on the webs at the beam ends (see Fig. 5). These specimens all failed by the flexural failure or by tensile material fracture at the mid-span of the beam. For the IOF loading condition in Fig. 6, the flanges and some parts of the webs at the mid-span reached the yield stress. This indicates that the failure of this specimen was caused by an interaction of flexural failure and web yielding.
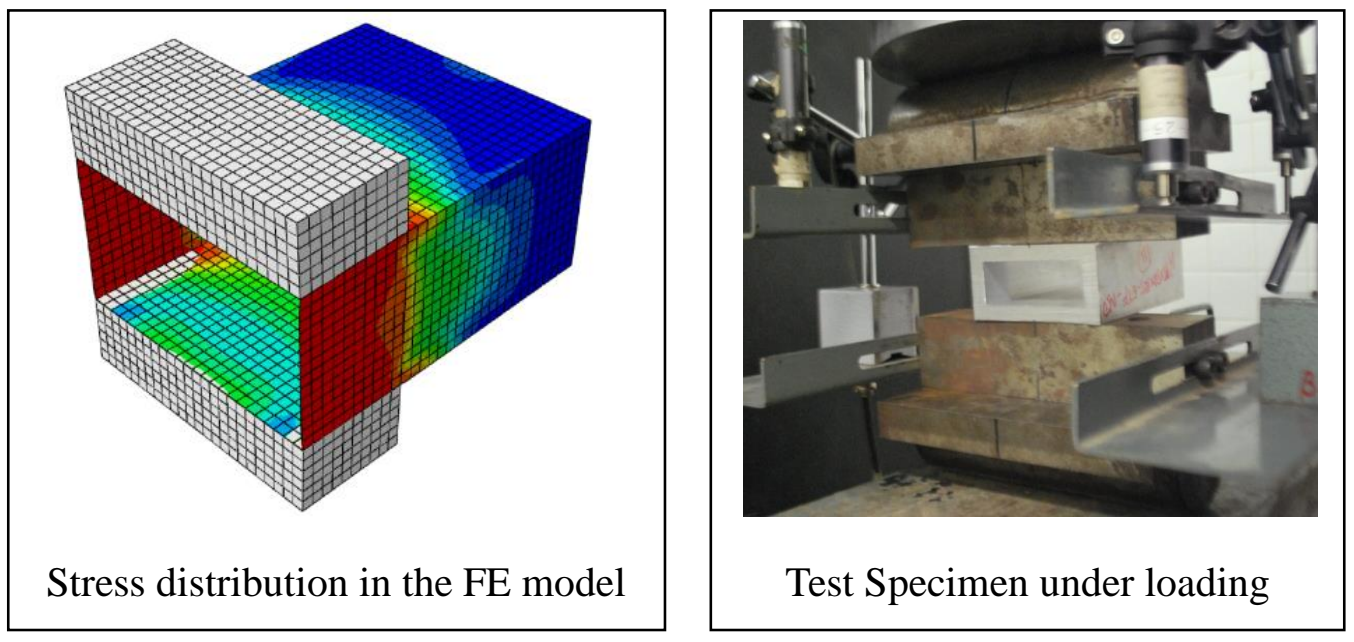

(a) $\mathrm{H} 95 \times 50 \times 10.5-\mathrm{ETF}-\mathrm{N} 50$
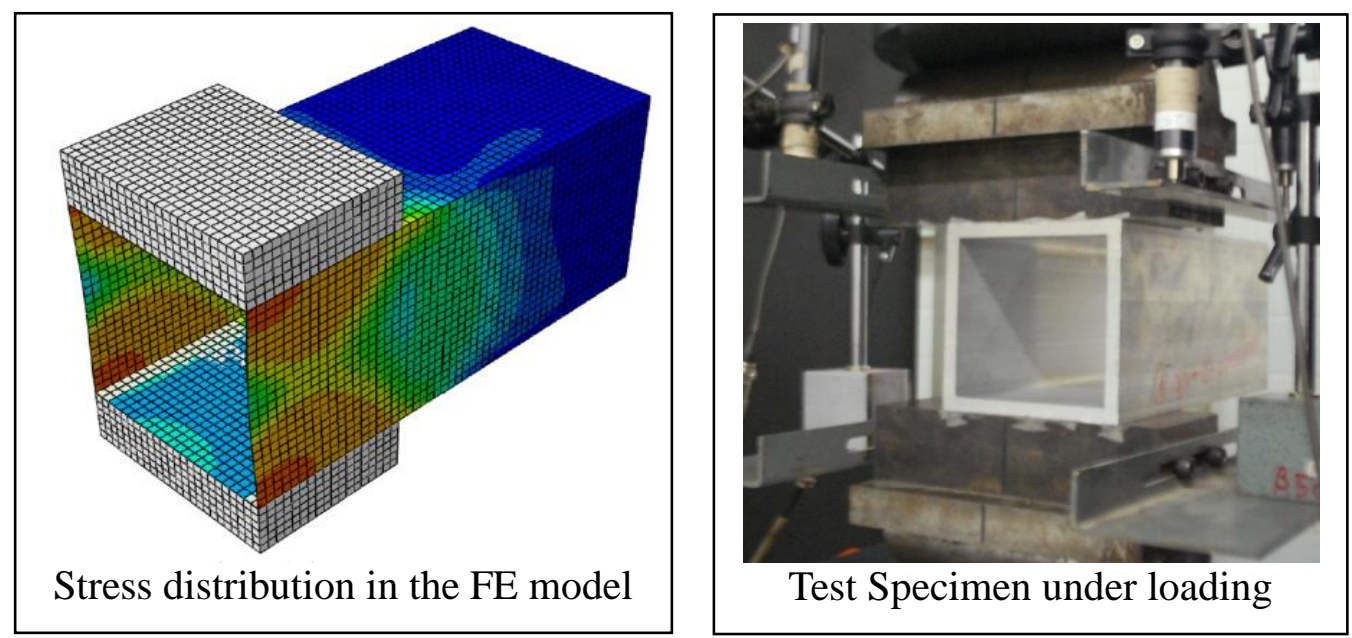

(b) N120×120×9.0-ETF-N90

Fig. 4: Comparison of web bearing failure modes from tests and FE models under ETF loading condition at their ultimate load. 

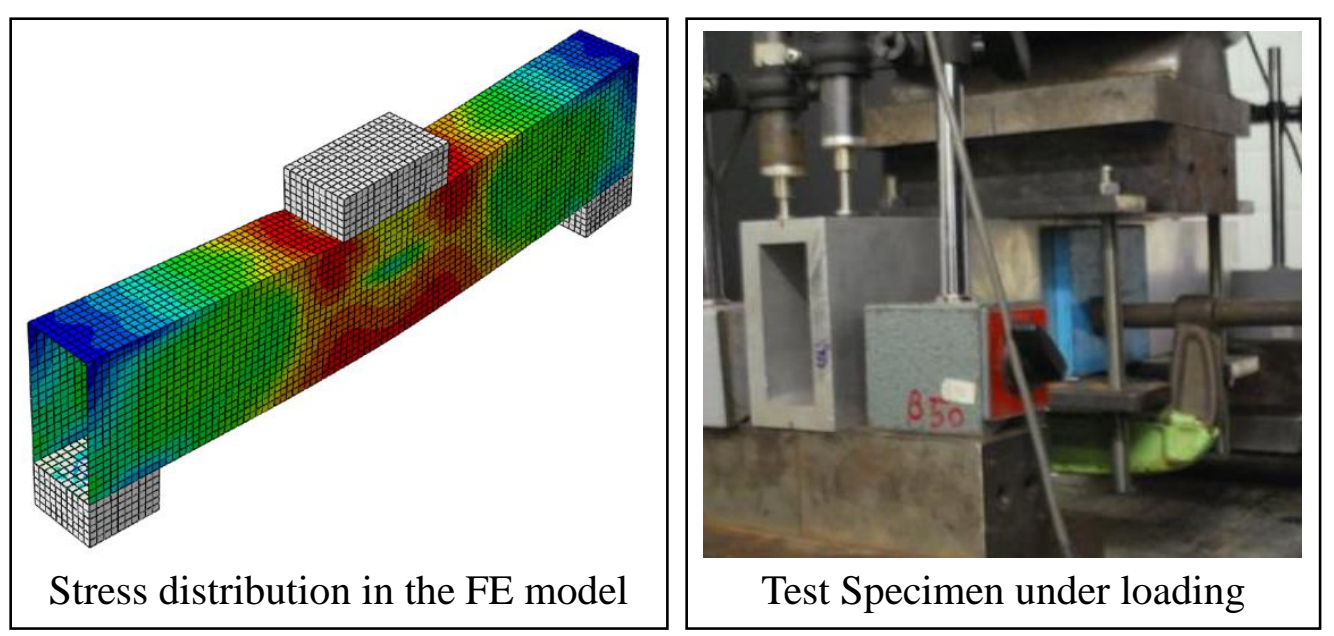

Fig. 5: Comparison of web bearing failure modes from tests and FE models under EOF loading condition at their ultimate load $(\mathrm{H} 95 \times 50 \times 10.5-\mathrm{EOF}-\mathrm{N} 50)$
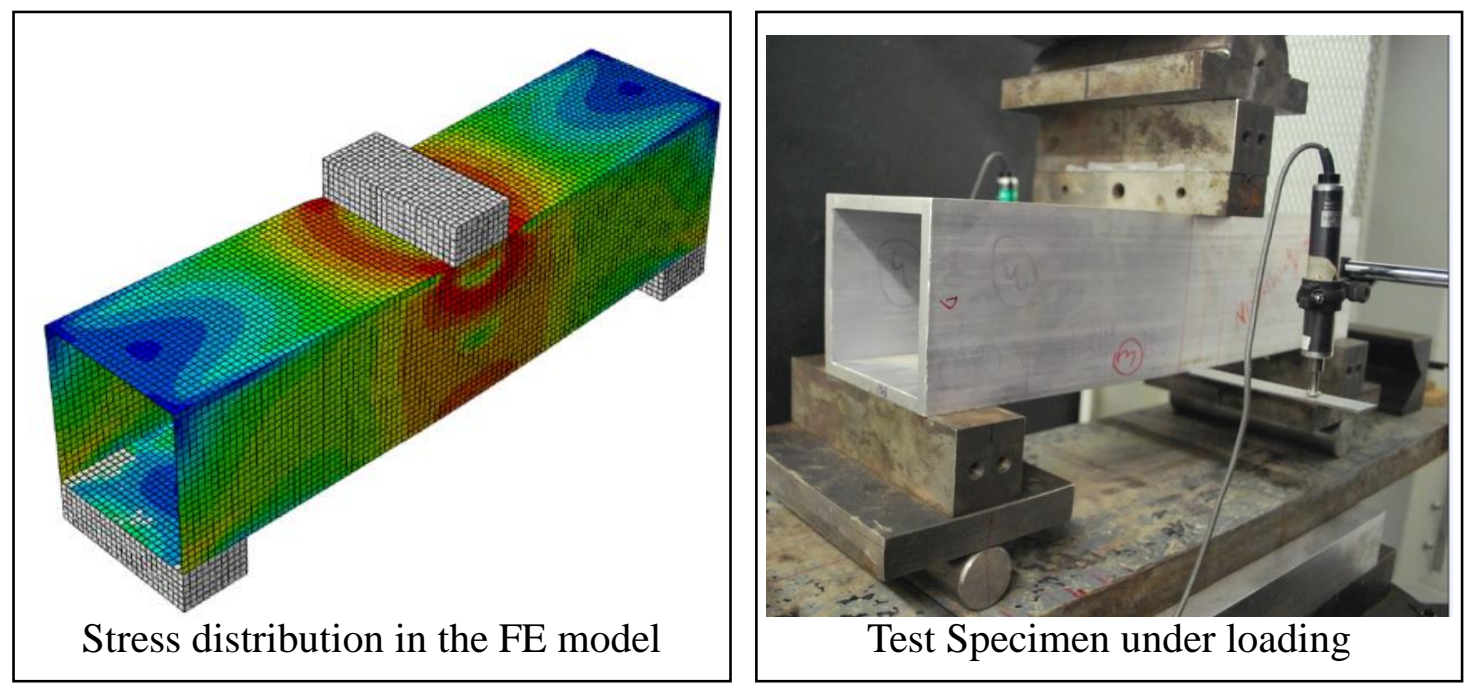

Fig. 6: Comparison of web bearing failure modes from tests and FE models under IOF loading condition at their ultimate load $(\mathrm{N} 120 \times 120 \times 9.0-\mathrm{ETF}-\mathrm{N} 90)$

The full load-deformation responses from all tests and simulations were compared. Typical load-web deformation curves are presented in Fig. 7 for the ETF loading condition and Fig. 8 for the EOF loading condition. In general, the initial stiffness and the shape of load-deformation curves are closely matched. The mean values of the $P_{\text {exp }} / P_{F E}$ ratio are 1.02 and 0.98 with the corresponding coefficient of variation $(\mathrm{COV})$ of 0.045 and 0.050 for the ETF and ITF loading conditions, respectively. The mean 
values of the $P_{\text {exp }} / P_{F E}$ ratio are 1.01 and 0.98 with the corresponding COV of 0.032 and 0.034 for the EOF and IOF loading conditions, respectively. A maximum difference of $9 \%$ from specimen H50×95×10.5-ITF-N90 was observed between the experimental and numerical results. Overall, it can be concluded that the FE models developed herein are able to replicate the behaviour of aluminium alloy specimens subjected to concentrated transverse loads.

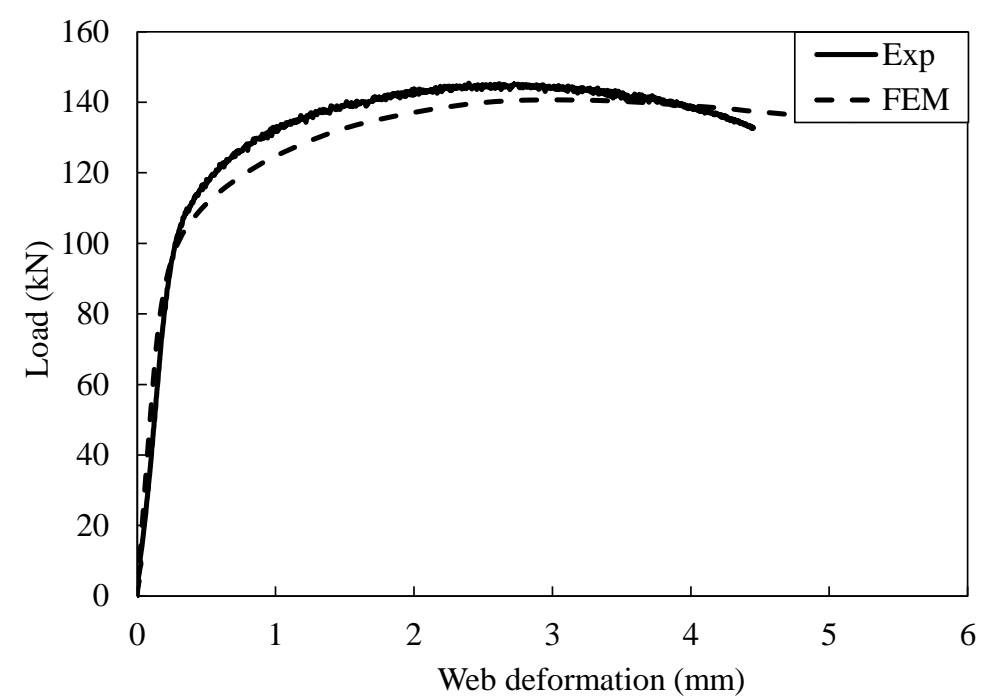

Fig. 7: Test and numerical load-web deformation curves for specimen H95 $\times 50 \times 10.5$-ETF-N50

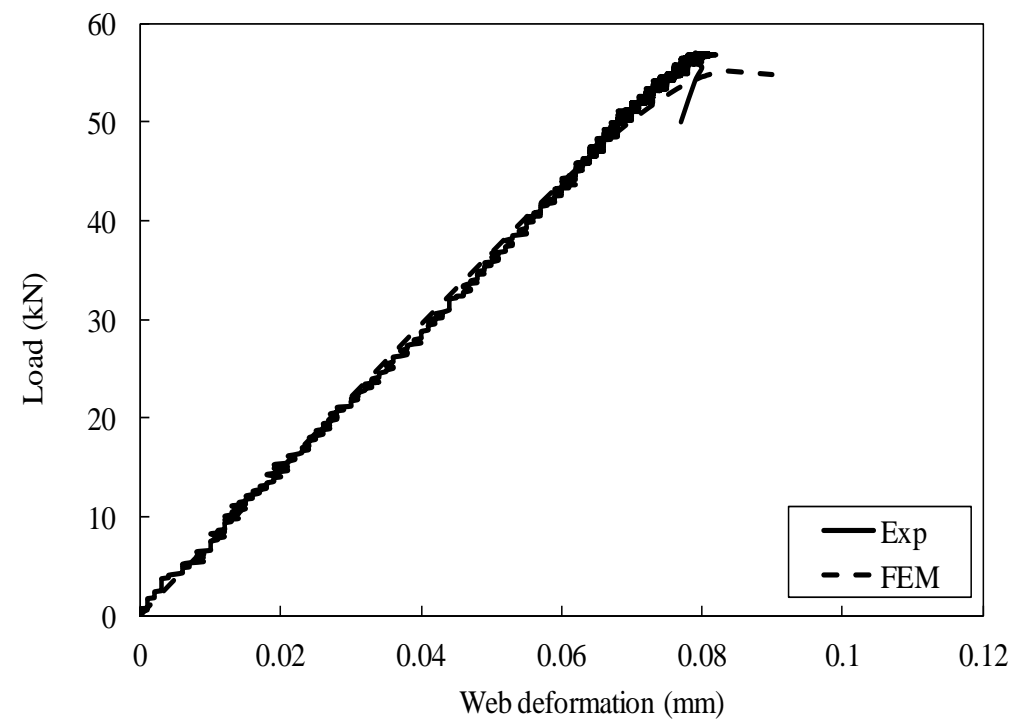

Fig. 8: Test and numerical load-web deformation curves for specimen H50×95×10.5-EOF-N50 
Table 5. Comparison between experimental and numerical results for the ETF loading condition

\begin{tabular}{|c|c|c|c|c|}
\hline Specimen & $\begin{array}{c}\text { Failure } \\
\text { mode }\end{array}$ & $\begin{array}{l}P_{e x p} \\
(\mathrm{kN})\end{array}$ & $\begin{array}{c}P_{F E} \\
(\mathrm{kN})\end{array}$ & $\frac{F_{\text {exp }}}{F_{F E}}$ \\
\hline H95×50×10.5-ETF-N50 & B & 145 & 141 & 1.03 \\
\hline H50×95×10.5-ETF-N50 & B & 142 & 131 & 1.08 \\
\hline H50×95×10.5-ETF-N50-R & B & 138 & 131 & 1.06 \\
\hline N120×70×10.5-ETF-N50 & B & 117 & 115 & 1.02 \\
\hline N70×120×10.5-ETF-N50 & B & 118 & 121 & 0.98 \\
\hline N120×120×9.0-ETF-N50 & B & 97 & 103 & 0.94 \\
\hline H95×50×10.5-ETF-N90 & B & 242 & 224 & 1.08 \\
\hline H50×95×10.5-ETF-N90 & B & 240 & 231 & 1.04 \\
\hline H120×70×10.5-ETF-N90 & B & 216 & 221 & 0.98 \\
\hline H70 $\times 120 \times 10.5$-ETF-N90 & B & 223 & 223 & 1.00 \\
\hline \multirow[t]{3}{*}{ N120×120×9.0-ETF-N90 } & B & 173 & 162 & 1.07 \\
\hline & & & Mean & 1.02 \\
\hline & & & $\mathrm{COV}$ & 0.045 \\
\hline
\end{tabular}

Table 6. Comparison between experimental and numerical results for the ITF loading condition

\begin{tabular}{|c|c|c|c|c|}
\hline Specimen & $\begin{array}{c}\text { Failure } \\
\text { mode }\end{array}$ & $\begin{array}{l}P_{\exp } \\
(\mathrm{kN})\end{array}$ & $\begin{array}{c}P_{F E} \\
(\mathrm{kN})\end{array}$ & $\frac{F_{\text {exp }}}{F_{F E}}$ \\
\hline H95×50×10.5-ITF-N50 & B & 210 & 237 & 0.93 \\
\hline H50×95×10.5-ITF-N50 & B & 223 & 223 & 1.00 \\
\hline N120×70×10.5-ITF-N50 & B & 219 & 212 & 1.04 \\
\hline N70 $\times 120 \times 10.5-\mathrm{ITF}-\mathrm{N} 50$ & B & 216 & 228 & 0.95 \\
\hline N120×120×9.0-ITF-N50 & B & 193 & 206 & 0.93 \\
\hline H95×50×10.5-ITF-N90 & B & 340 & 331 & 1.03 \\
\hline H50×95×10.5-ITF-N90 & B & 310 & 308 & 1.01 \\
\hline H50×95×10.5-ITF-N90-R & B & 281 & 294 & 0.96 \\
\hline N120×70×10.5-ITF-N90 & B & 297 & 286 & 1.04 \\
\hline N70 $\times 120 \times 10.5-$ ITF-N90 & B & 259 & 279 & 0.93 \\
\hline \multirow[t]{3}{*}{ N120×120×9.0-ITF-N90 } & B & 241 & 265 & 0.91 \\
\hline & & & Mean & 0.98 \\
\hline & & & $\mathrm{COV}$ & 0.050 \\
\hline
\end{tabular}


Table 7. Comparison between experimental and numerical results for the EOF loading condition

\begin{tabular}{|c|c|c|c|c|}
\hline Specimen & $\begin{array}{c}\text { Failure } \\
\text { mode }\end{array}$ & $\begin{array}{l}P_{\exp } \\
(\mathrm{kN})\end{array}$ & $\begin{array}{l}P_{F E} \\
(\mathrm{kN})\end{array}$ & $\frac{F_{\text {exp }}}{F_{F E}}$ \\
\hline H95×50×10.5-EOF-N50 & $\mathrm{F}$ & 53 & 50 & 1.05 \\
\hline H50×95×10.5-EOF-N50 & $\mathrm{F}$ & 57 & 56 & 1.03 \\
\hline H50×95×10.5-EOF-N50-R & $\mathrm{F}$ & 58 & 58 & 0.99 \\
\hline $\mathrm{N} 120 \times 70 \times 10.5-\mathrm{EOF}-\mathrm{N} 50$ & $\mathrm{~F}$ & 65 & 62 & 1.03 \\
\hline $\mathrm{N} 70 \times 120 \times 10.5-\mathrm{EOF}-\mathrm{N} 50$ & $\mathrm{~F}$ & 77 & 80 & 0.97 \\
\hline \multirow[t]{3}{*}{$\mathrm{N} 120 \times 120 \times 9.0-\mathrm{EOF}-\mathrm{N} 50$} & S & 89 & 89 & 1.01 \\
\hline & & & Mean & 1.01 \\
\hline & & & $\mathrm{COV}$ & 0.032 \\
\hline
\end{tabular}

Table 8. Comparison between experimental and numerical results for the IOF loading condition

\begin{tabular}{|c|c|c|c|c|}
\hline Specimen & $\begin{array}{c}\text { Failure } \\
\text { mode }\end{array}$ & $\begin{array}{l}P_{\text {exp }} \\
(\mathrm{kN})\end{array}$ & $\begin{array}{c}P_{F E} \\
(\mathrm{kN})\end{array}$ & $\frac{F_{\text {exp }}}{F_{F E}}$ \\
\hline $\mathrm{H} 95 \times 50 \times 10.5-\mathrm{IOF}-\mathrm{N} 50$ & $\mathrm{~F}+\mathrm{B}$ & 102 & 100 & 1.02 \\
\hline H50×95×10.5-IOF-N50 & $\mathrm{S}+\mathrm{B}$ & 105 & 111 & 0.95 \\
\hline H50×95×10.5-IOF-N50-R & $\mathrm{S}+\mathrm{B}$ & 112 & 112 & 1.00 \\
\hline N120×70×10.5-IOF-N50 & $\mathrm{F}+\mathrm{B}$ & 117 & 123 & 0.95 \\
\hline N70×120×10.5-IOF-N50 & $\mathrm{S}+\mathrm{B}$ & 159 & 161 & 0.99 \\
\hline \multirow[t]{3}{*}{ N120×120×9.0-IOF-N50 } & $\mathrm{F}+\mathrm{B}$ & 150 & 159 & 0.95 \\
\hline & & & Mean & 0.98 \\
\hline & & & $\mathrm{COV}$ & 0.034 \\
\hline
\end{tabular}

\section{Parametric study}

The validated FE models provide a basis for a parametric study aiming to better the understanding of the behaviour of tubular sections subjected to web bearing failure. A parametric study was performed to investigate the effects of three key factors on the aluminium alloy web resistances: the web slenderness, the yield strength, and the bearing length.

Since this study is focused on web bearing design, the selection of appropriate specimens that failed by web bearing is very important. A feasibility study on the $h / t$ 
limits was carried out to exclude slender sections that failed by web buckling. Specimens with a wide range of $h / t$ ratio were modelled under the ETF and ITF loading conditions. The failure mode of web bearing under the ETF loading condition is shown in Fig. 4. If the section is too slender, web buckling was observed with large deflection at the mid-length of the webs, as shown in Fig. 9. The yielding at the mid-height of the web is the load concentration due to the curvature of the web caused by buckling. The critical $h / t$ limit above which specimens failed by web buckling was found to be 28.0. This corresponds to the specimen H150X150X3.5-ETF-N90, where the stress at the mid-length of the webs just reached the yield stress at the ultimate load (see Fig. 10). When the $h / t$ ratio is larger than 28.0, the stress at the mid-length of the webs reached the yield stress at the ultimate load; whereas when the $h / t$ ratio is smaller than 28.0, the stress at the mid-length of the webs has not yet reached the yield stress at the ultimate load. Therefore, to include only the web bearing failure results, the $h / t$ ratio of 28.0 is chosen as the upper bound limit for the parametric study of this research.

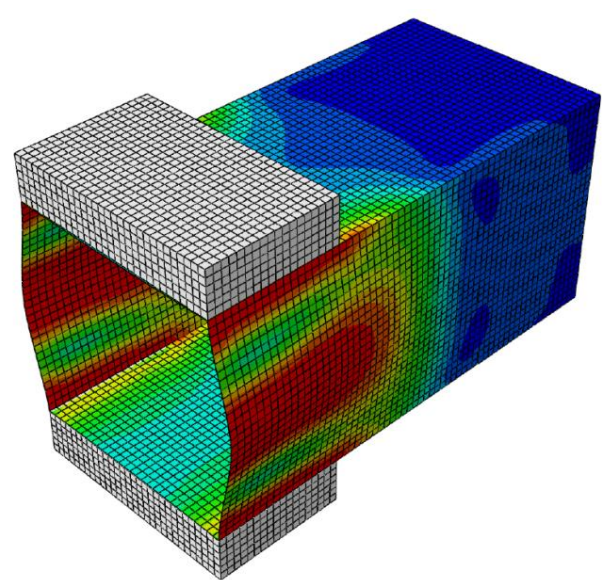

Fig. 9: FE failure mode (web buckling) for specimen H150X150X2.0-ETF-N90 


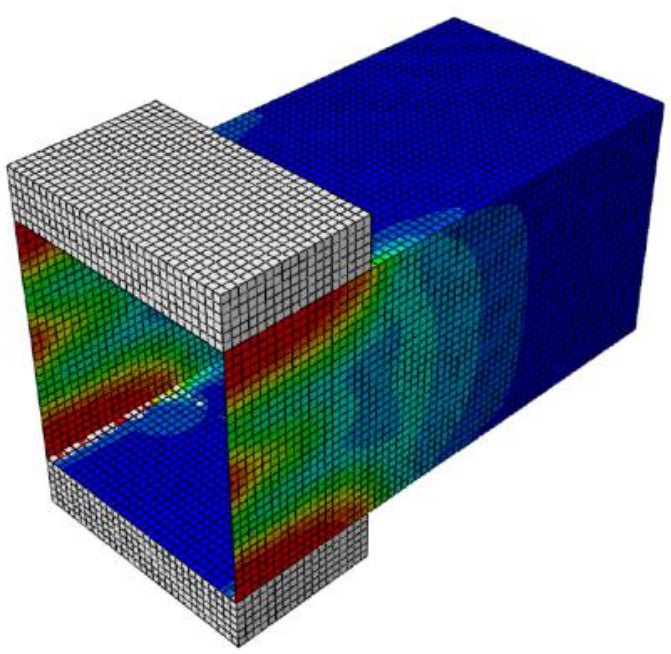

Fig. 10: FE failure mode (Interaction of web bearing and web buckling) for specimen

H150X150X3.5-ETF-N90

A series of 84 numerical results (21 under each loading conditions) were generated in the parametric study. A total of 5 different cross-section dimensions were modelled, with outer wall dimensions up to $150 \mathrm{~mm}$ with the thickness varying between $5.0 \mathrm{~mm}$ and $9.0 \mathrm{~mm}$. When including the experimental results, the web slenderness ratios from 2.80 to 28.0 for four cross-section classes have been considered in this study. The stress-strain material curves obtained from the tensile coupon tests of specimen H50 $\times 95 \times 10.5$-ETF-N90 (with $f_{y}=232.0 \mathrm{MPa}$ and $f_{u}=244.5 \mathrm{MPa}$ ) and N120 $\times 70 \times 10.5$-ETF-N50 (with $f_{y}=139.1 \mathrm{MPa}$ and $f_{u}=194.0 \mathrm{MPa}$ ) were used to define material properties of high strength and normal strength aluminium alloys respectively in the parametric study. All the FE models in the parametric study were reviewed to ensure that no web buckling failure occurred. The specimens under ETF and ITF loading conditions were observed to fail by web bearing. For the EOF and the IOF loading conditions, web bearing failure was not apparent since the web 
deformation at the ultimate load was less than $0.5 \%$ for all models of these loading conditions. Instead, the flexural effect seems to play a more important role in failure. This observation will be further discussed in the coming section.

\section{Comparison with design methods}

In this section, the experimental and numerical results of aluminium alloy square and rectangular hollow sections subjected to concentrated loads are compared with existing design methods. No specimens which failed by web buckling are included in this section since this study focuses on web bearing design owing to material yielding. The web bearing design strengths were predicted according to the AA [15], the AS/NZS [16] EC9 [17], AISC [18], the AS4100 [19] and EC3[20] specifications.

\subsection{Aluminium design manual [15]}

The three aforementioned design standards were established for steel materials, while the Aluminum Design Manual [15] is a standard for aluminium alloy structural members. The web design rules for webs subjected to a concentrated transverse load are specified in clause J9.1. The AA specification does not separate the web design by the failure modes. This means that the same design rules are adopted for webs that fail by local buckling and those that fail by material yielding. The standard has equations for end bearing (i.e. ETF and EOF) and internal bearing (i.e. ITF and IOF) conditions. The web design for ETF and EOF is given by Eq. (3):

$P_{A A}=\frac{1.2 t^{2}\left(0.46 f_{y}+0.02 \sqrt{E f_{y}}\right)(N+33)}{10}$ 
The web design for ITF and IOF loading conditions is given by Eq. (4):

$P_{A A}=\frac{t^{2}\left(0.46 f_{y}+0.02 \sqrt{E f_{y}}\right)(N+140)}{10}$

\subsection{Australian/New Zealand Standards [16]}

The Australian/New Zealand Standard [16] for aluminium alloy structures has adopted the web design rules from the AA specification. Therefore, the AS/NZS $\left(P_{A S / N Z S}\right)$ and AA $\left(P_{A A}\right)$ specifications provide the identical web bearing design predictions.

\subsection{Eurocode 9 [17]}

Eurocode 9 [17] provides resistance design rules for webs subjected to transverse loads in clause 6.7.5. EC9 provides design equations for web buckling failure and an upper bound limit which corresponds to web bearing failure. The design expressions are given below, from Eqs. (5) to (14). The principle of the design is given in Eq. (5), while the upper bound design of this equation given by Eq. (6), which corresponds to web bearing failure. The concentrated load was assumed to spread out at a slope of 1:1 through a specimen. It should be noted that only three loading conditions, i.e. EOF, ITF and IOF, are specified in EC9 for aluminium alloy structures. For cases of the ETF loading condition in this study, the EC9 EOF design rules are used. The ETF loading case can only refer to the design rules of EOF loading condition.

$$
P_{E C 9}=\chi_{F} b_{y} t f_{y}
$$




$$
\begin{aligned}
& \chi_{F}=\frac{0.5}{\lambda_{F}} \leq 1.0 \\
& \lambda_{F}=\sqrt{\frac{b_{y} t f_{y}}{F_{c r}}} \\
& F c r=\frac{0.9 k_{F} E t^{3}}{h}
\end{aligned}
$$

For the EOF and ETF loading conditions:

$$
k_{F}=2+6\left(\frac{N}{h}\right) \leq 6
$$

$b_{y}=$ least of $\left\{\begin{array}{l}N+2 t\left(1+\sqrt{m_{1}+m_{2}}\right) \\ l_{e}+t \sqrt{\frac{m_{1}}{2}+\left(\frac{l_{e}}{t}\right)^{2}+m_{2}} \\ \left.l_{e}+t \sqrt{m_{1}+m_{2}}\right)\end{array}\right\}$

$l_{e}=\frac{k_{F} E t^{2}}{2 f_{y} h} \leq N$

For the ITF loading condition:

$$
\begin{aligned}
& k_{F}=3.5+2\left(\frac{h}{L}\right)^{2} \\
& b_{y}=N+2 t\left(1+\sqrt{m_{1}+m_{2}}\right)
\end{aligned}
$$

For the IOF loading condition:

$$
\begin{aligned}
& k_{F}=6+2\left(\frac{h}{L}\right)^{2} \\
& b_{y}=N+2 t\left(1+\sqrt{m_{1}+m_{2}}\right)
\end{aligned}
$$

where:

$\chi_{\mathrm{F}}$ is the reduction factor due to local buckling 
$k_{F}$ is the buckling factor for transverse force

$\lambda_{F}$ is the slenderness parameter for local buckling due to transverse force

$F_{c r}$ is the elastic critical buckling load for global instability mode based on initial elastic stiffness

$m_{1}, m_{2}$ and $l_{e}$ are parameters in formulae for effective loaded length with: $m_{1}=\frac{B}{2 t}$ for SHS/RHS $m 2=0.02\left(\frac{h}{t}\right)^{2}$ if $\lambda_{F}>0.5$, otherwise $m_{2}=0$

\subsection{AISC specification [18]}

The AISC Specification for Structural Steel Buildings [18] provides the web local yielding design in clause J10.2. Design rules for web bearing strengths are divided into two cases, according to the load concentrated location. It should be noted that the web yielding design rules in the AISC were only initially developed for one-flange loading (EOF and IOF) conditions, but were then adopted for the two-flange loading (ETF and ITF) conditions. Thus there are no specific design rules for two-flange loading conditions. The design provisions of AISC were based on tests on two-sided directly welded girder-to-column connections [31]. The stress slope that spreads out in the flange was originally assumed as 2:1, but later on, a more accurate stress gradient of 2.5:1 was suggested by Graham et al. [32], which is used here. The web bearing resistance is defined in Eq. (15):

$P_{\text {AISC }}=b_{y} t f_{y}$ 
where $b_{y}$ is the yielding length at the webs, $t$ is web thickness, and $f_{y}$ is the yield stress.

For the ETF and EOF loading conditions:

$b_{y}=2.5 t+N \geq 3.5 t$

For the ITF and IOF loading conditions:

$b_{y}=5 t+N$

where $N$ is the bearing length.

Recent studies indicated that the predictions given by Eq. (15) were slightly conservative $[33,34]$.

\subsection{AS4100 [19]}

An equation to determine web bearing yield capacity is provided in clause 5.13.3 in the Australian Standards for Steel Structures AS4100 [19]. The general design rules in AS4100 [19] as shown in Eq. (18) are similar to that of the AISC [18], except it includes a coefficient, $\alpha_{p}$, that is specified for SHS/RHS.

$P_{A S 4100}=b_{y} t f_{y} \alpha_{p}$

Here, $b_{y}$ and $\alpha_{p}$ for the ETF and EOF loading conditions are given in Eqs. (19) and (20):

$b_{y}=N+2.5 t+0.5 h$

$\alpha_{p}=2.73$

For the ITF and IOF loading conditions, $b_{y}$ and $\alpha_{p}$ are given in Eqs. (21) and (22):

$b_{y}=N+5 t+h$ 


$$
\alpha_{p}=-\frac{1}{2}\left\{1+\left(\frac{t}{h}-\frac{t^{2}}{4 h^{2}}\right)\left[1-\frac{t}{h}-\frac{t^{2}}{4 h^{2}}\left(\frac{t}{h}-\frac{t^{2}}{4 h^{2}}\right)\right]\right\}
$$

\subsection{EC1993-1-3 [20]}

Eurocode 3 - Design of steel structures EN 1993-1-3 (EC3) [20] provides design provisions to calculate the web crippling strength in Section 6.1.7 [20]. Since this study focuses on the SHS/RHS, which are the sections with two webs, the design procedure and coefficients for ETF, ITF, EOF and IOF loading conditions should refer to Section 6.1.7.3 [20] particularly. EC3 classifies the different loading conditions into two categories only. The EOF, ETF and ITF loading conditions are belonged to Category 1 and the IOF loading condition is belonged to Category 2. The design capacity $P_{E C 3}$ can be calculated by Eq. (23).

$$
P_{E C 3}=3.4 \alpha t^{2} \sqrt{E f_{y}}\left(0.5+\sqrt{\frac{0.02 b_{y}}{t}}\right)
$$

For the EOF, ETF and ITF loading conditions:

$\alpha=0.057$, is the web crippling coefficient

$b_{\mathrm{y}}=10 \mathrm{~mm}$

For the IOF loading condition:

$\alpha=0.115$, is the web crippling coefficient

$b_{\mathrm{y}}=N$ 


\subsection{Comparison of results}

The experimental and numerical ultimate web bearing load per web $\left(P_{u}\right)$ values are compared with the nominal design strengths predicted by the aforementioned six design methods. The comparison between the experimental and numerical results and the design capacities are plotted in Fig. 11 and summarized in Table 9. Since the predictions of the EC3 are significantly conservative for the ETF and ITF loading conditions, the comparison with EC3 are not plotted Figs.11(a) and (b) in order to keep a reasonable scale to clearly show the differences of the other design methods. The design strengths were calculated using the measured cross-section dimensions of each specimen and the measured material properties.

For the ETF loading condition, both steel based codes - AISC and AS4100 provide generally unsafe design strengths $\left(P_{u} / P_{A I S C}=0.87\right.$ and $\left.P_{u} / P_{A S 4100}=0.80\right)$. Similarly, the Eurocode $9\left(P_{u} / P_{E C 9}=0.87\right)$ is also generally unsafe. The coefficient of variation $(\mathrm{COV}=0.115)$ for the AISC is least scatter of these codes. The remaining two aluminium alloy based codes, AA and AS/NZS, have better predictions as their mean values are closer to unity $\left(P_{u} / P_{A A}\right.$ and $\left.P_{u} / P_{A S / N Z S}=0.96\right)$ and have acceptable COV values $(\mathrm{COV}=0.143)$. On the contrary, EC3 is the only design code providing significantly conservative predictions $\left(P_{u} / P_{E C 3}=5.05\right)$, which is mainly due to the constant bearing length of $10 \mathrm{~mm}$. This bearing length is codified for EOF, ETF and ITF loading conditions despite the fact that the test specimens were loaded by different bearing lengths. When considering Fig. 12(a), the difference between the 
experimental tests and numerical results-to-predicted values of the AISC and AS4100 methods decrease as the web slenderness $h / t$ ratio becomes greater. The predictions from the AA and AS/NZS show a different trend; the design becomes more conservative as the $h / t$ ratio increases. This overestimation of the web bearing strengths of relatively stocky sections by the AA and the AS/NZS specifications results from the fact these two specifications were based on web crippling failure with no consideration of web bearing failure.

Regarding to the ITF loading condition, the performance of the AISC $\left(P_{u} / P_{\text {AISC }}=1.19\right.$ and $\mathrm{COV}=0.116)$ is much better than the other steel code, i.e. the AS4100 $\left(P_{u} / P_{A S 4100}\right.$ $=1.57$ and $\mathrm{COV}=0.491)$ and $\mathrm{EC} 3\left(P_{u} / P_{E C 3}=8.04\right.$ and $\left.\mathrm{COV}=0.236\right)$. The prediction by EC3 is significant conservative, which shows that EC3 is not appropriate for the web bearing design for aluminium alloy tubular sections. Similar to the ETF loading condition, the predictions of the AA and AS/NZS provide unsafe design strengths for stocky sections and conservative strengths for less stocky sections. The overall predictions of the AA and AS/NZS are quite accurate $\left(P_{u} / P_{A A}\right.$ and $P_{u} / P_{A S / N Z S}=1.00$ and COV $=0.157$ ), in spite of the rules being based on the web buckling failure mode. By comparison, the design strengths from EC9 are a bit more conservative but show less scatter $\left(P_{u} / P_{E C 9}=1.16\right.$ and $\left.\mathrm{COV}=0.111\right)$.

Though the one flange loading tests have been conducted according to the requirements found in different specifications, the failure modes of these specimens 
were still affected by flexural. In the case of the EOF loading condition, it was found that all of the most of the design rules have overestimated the ultimate loads $P_{u}$ except EC3, as shown in Table 9(c) and Fig. 11(c). Most of the web bearing design rules are seen to have overestimated the results of the experimental and numerical loads by approximately twice their values. The comparison results for the IOF loading condition is similar to those discussed for the EOF loading condition. The design codes are generally non-conservative except for AS4100 and EC3, as shown in Fig. 11(d). As indicated by the test results and failure modes, the ultimate capacities of specimens under one-flange loading conditions (EOF and IOF) were affected significantly by bending effects. As for EOF loading condition, web bearing design rules might not be necessary, since these members fail either by web buckling (for slender sections) or by flexural failure (for non-slender sections). While for relatively stocky sections under IOF loading condition, flexural behaviour has significant effect on the ultimate capacities of specimens. The combined bending moment and concentrated load could cause a reduction of capacity below that for the moment or concentrated load alone [35].

\section{Proposed design equations for web bearing}

As discussed in the last section, the generated results under EOF and IOF loading conditions in this study has been significantly affected by flexural behaviour. Therefore, only web bearing design rules for the ETF and ITF loading conditions are proposed herein. 
The strain hardening behaviour of aluminium alloys has been well studied in recent research works $[14,36]$. Similar to cross-sections subjected to compression or bending, stocky webs that fail by web bearing may be able sustain more loading beyond the yield stress. In the present study, the effect of strain hardening is taken into account for the proposed web bearing design rules.

\subsection{Design method with consideration of strain hardening}

The web bearing failure mechanism is where webs under concentrated loads reach yielding stresses. The web bearing design capacity is the yielding area $\left(b_{y} t\right)$ multiplied by the resisting stress $\left(f_{c s m}\right)$. As explained in the continuous strength method (CSM) $[14,36,37]$, the CSM limiting stress $f_{c s m}$ includes the strain hardening effect. To include the strain hardening effect, the present study uses the CSM stress $f_{c s m}$ is to replace the yield stress $f_{y}$, as shown in Eq. (24). By including strain hardening in the design equations, material properties of different aluminium alloys can be considered more specifically. The proposed design procedure for determining the web bearing strength of aluminium alloys for two flange loading conditions is given below:

$P_{\text {prop. }}=b_{y} t f_{c s m}$

where:

$f_{\text {csm }}$ is the limited CSM stress given by:

$f_{c s m}=f_{y}+E_{s h}\left(\varepsilon_{c s m}-\varepsilon_{y}\right)$ 
$E_{s h}$ is the strain hardening slope given by:

$E_{s h}=\frac{f_{u}-f_{y}}{0.5 \varepsilon_{u}-\varepsilon_{y}}$

$\varepsilon_{c s m}$ is the CSM strain given by:

$$
\varepsilon_{c s m}=\frac{0.25}{\bar{\lambda}_{p}^{3.6}} \varepsilon_{y} \text { but } \varepsilon_{\mathrm{y}} \leq \varepsilon_{c s m} \leq \text { lesser of }\left(15 \varepsilon_{\mathrm{y}}, \quad 0.5 \varepsilon_{u}\right)
$$

$\lambda_{p}$ is the plate slenderness given by:

$\bar{\lambda}_{p}=\sqrt{f_{y} / f_{c r}}$

$\varepsilon_{u}$ is the tensile strain at the ultimate stress given by:

$\varepsilon_{\mathrm{u}}=0.13\left(1-f_{y} / f_{u}\right)+0.06$

$\varepsilon_{\mathrm{y}}$ is the yield strain given by:

$\varepsilon_{\mathrm{y}}=f_{y} / E$

For the ETF loading condition:

$b_{y}=0.8(N+2.5 t)$

For the ITF loading condition:

$b_{y}=N+5 t$

It should be noted that when calculating the critical buckling stress $f_{c r}$ for Eq. (28), the plate coefficient $k$ is 1.247 for ETF loading condition and 6.97 for ITF loading condition. The proposed design rules were calibrated based on the experimental and 
numerical results and may not adequately account for sections and bearing lengths outside the range of variables tested.

\subsection{Comparison of results}

The result comparisons are conducted between the experimental and numerical results and the for the proposed design method $\left(P_{\text {prop }}\right)$, and are presented in Fig. 12 and Table 9. The proposed design strengths are generally reliable for both ETF and ITF loading conditions. The mean value of tested and numerical-to-predicted load ratio is 1.05 with the corresponding COV of 0.083 for the ETF loading condition, while the mean value of tested and numerical-to-predicted load ratio is 1.05 with the corresponding COV of 0.067 for ITF loading condition. In both cases, the proposed design rules have provided more accurate mean values and lower COV compared to the previously reviewed existing design rules.

Reliability analyses are conducted for the newly proposed design rules as well as current design codes for the ETF and ITF loading conditions, and shown in Table 9. The reliability index $\beta$ is calculated in accordance with clause 1.3.2 of Appendix 1, Part I in the AA standard [15], where the mean values and COVs for material properties and fabrication variables are taken as $M_{m}=1.10$ for behaviour governed by the yield stress and $M_{m}=1.00$ for behaviour governed by the ultimate stress, $F_{m}=$ 1.00, $V_{M}=0.06$, and $V_{F}=0.05$. A load combination of 1.2DL +1.6LL (where DL and LL signify dead loads and live loads, respectively) from the AA standard [15] is 
adopted herein. The resistance factor of aluminium alloy members is assumed as 0.90 [15]. The minimum required reliability index for aluminium alloy members is 2.50 , as codified in the AA standard [15]. It is seen that for the ETF loading condition, only the newly proposed method can pass the reliability analyses for web bearing design. As for the ITF loading condition, the AISC, EC9 and the newly proposed method are seen to be safe and reliable.

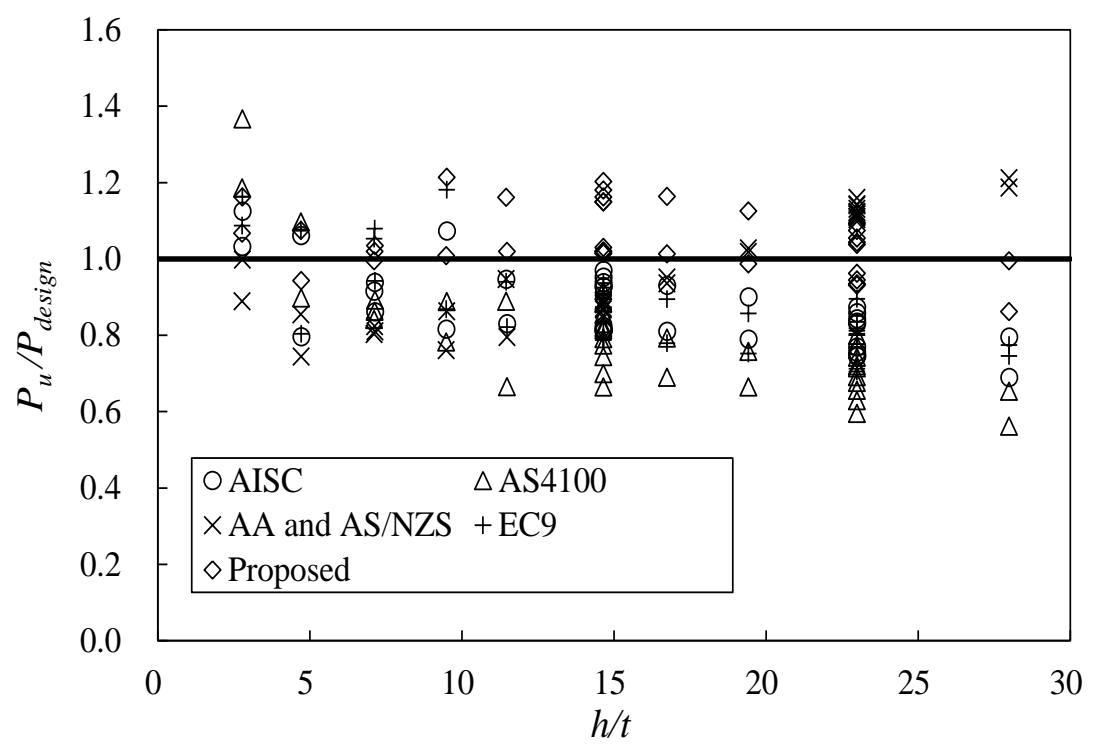

(a) ETF loading condition

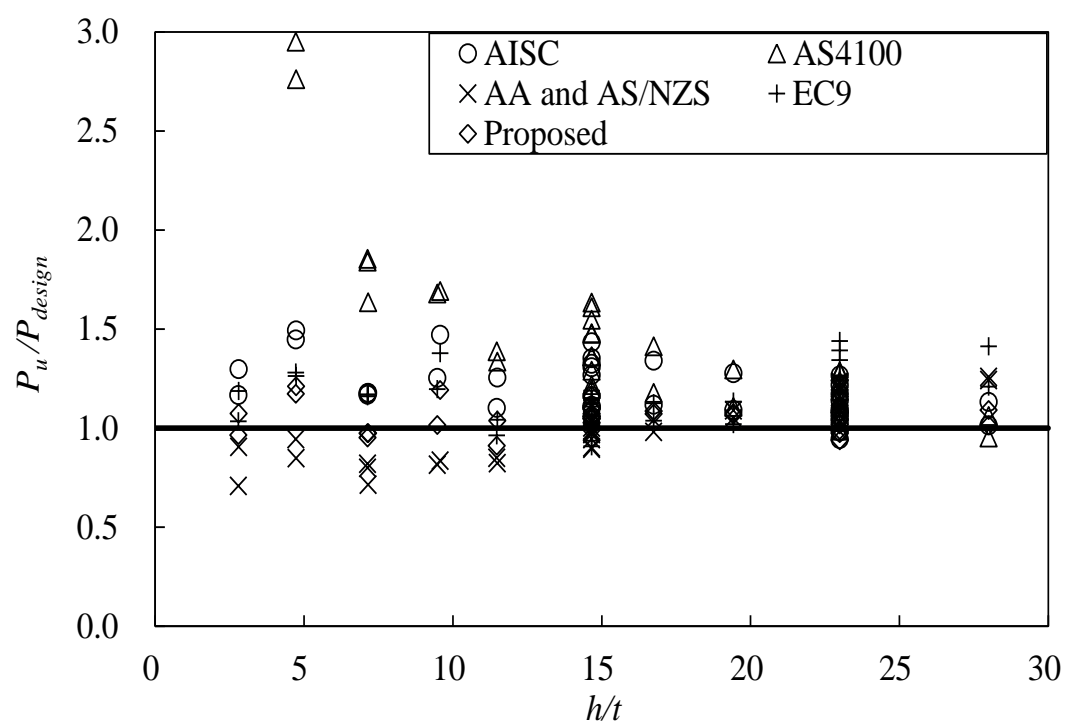

(b) ITF loading condition 


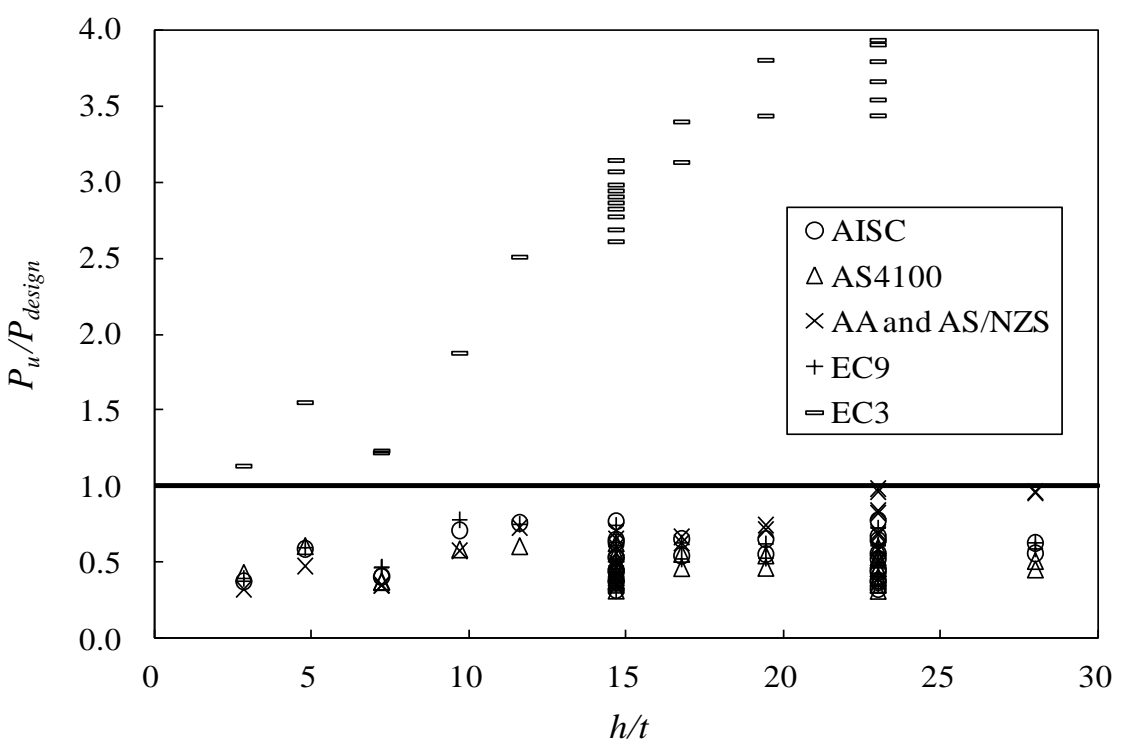

(c) EOF loading condition

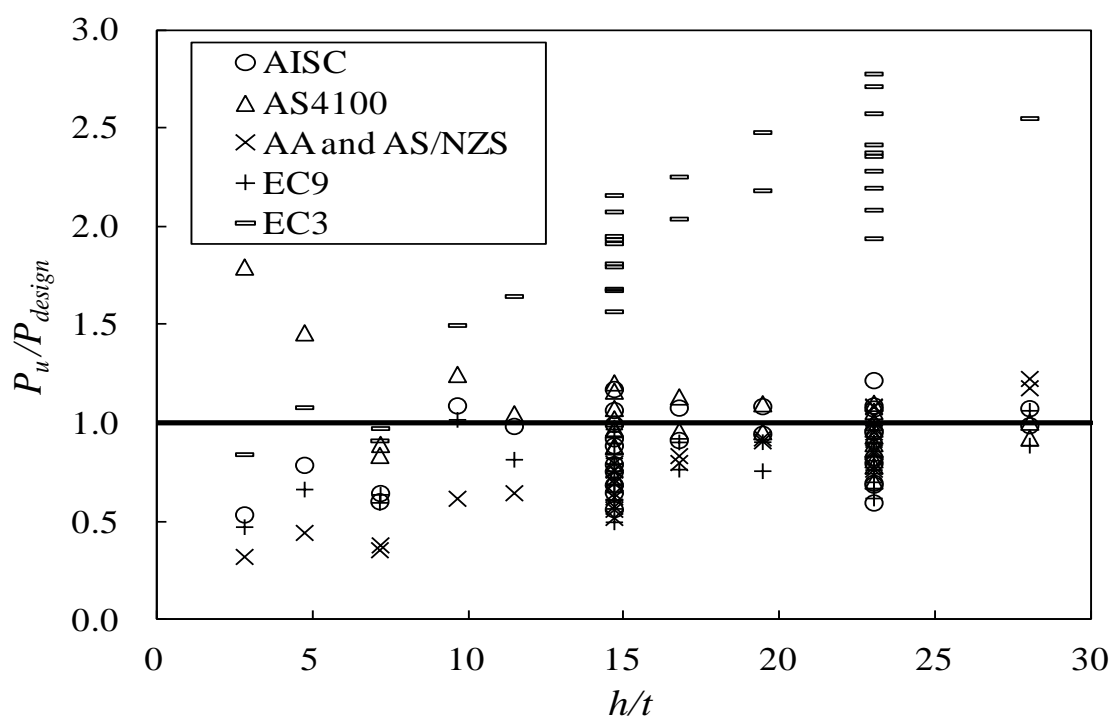

(d) IOF loading condition

Fig. 11: Comparison of test strengths with design strengths for (a) ETF, (b) ITF, (c) EOF and (d) IOF loading conditions 
Table 9. Comparison between test results and design strengths for each loading condition

\begin{tabular}{|c|c|c|c|c|c|c|c|c|c|c|}
\hline \multirow{2}{*}{$\begin{array}{l}\text { Test } \\
\text { configuration }\end{array}$} & \multicolumn{4}{|c|}{ ETF } & \multicolumn{2}{|c|}{ ITF } & \multicolumn{2}{|c|}{ EOF } & \multicolumn{2}{|c|}{ IOF } \\
\hline & Mean & $\mathrm{COV}$ & $\beta$ & Mean & $\mathrm{COV}$ & $\beta$ & Mean & $\mathrm{COV}$ & Mean & $\mathrm{COV}$ \\
\hline $\begin{array}{l}\text { Number of } \\
\text { specimens }\end{array}$ & & 37 & & & 37 & & 32 & & 3 & \\
\hline$\frac{P_{u}}{P_{A A}}$ & 0.96 & 0.143 & 2.11 & 1.00 & 0.157 & 2.20 & 0.47 & 0.194 & 0.78 & 0.303 \\
\hline$\frac{P_{u}}{P_{A S / N Z S}}$ & 0.96 & 0.143 & 2.11 & 1.00 & 0.157 & 2.20 & 0.62 & 0.316 & 0.78 & 0.303 \\
\hline$\frac{P_{u}}{P_{E C 9}}$ & 0.87 & 0.140 & 1.76 & 1.16 & 0.111 & 2.99 & 0.53 & 0.234 & 0.78 & 0.194 \\
\hline$\frac{P_{u}}{P_{A I S C}}$ & 0.87 & 0.115 & 1.82 & 1.19 & 0.116 & 3.07 & 0.54 & 0.253 & 0.88 & 0.220 \\
\hline$\frac{P_{u}}{P_{A S 4100}}$ & 0.80 & 0.201 & 1.23 & 1.57 & 0.491 & 1.89 & 0.47 & 0.194 & 1.01 & 0.211 \\
\hline$\frac{P_{u}}{P_{E C 3}}$ & 5.05 & 0.298 & 5.82 & 8.04 & 0.236 & 8.07 & 3.14 & 0.306 & 2.00 & 0.271 \\
\hline$\frac{P_{u}}{P_{\text {prop }}}$ & 1.05 & 0.083 & 2.66 & 1.05 & 0.067 & 2.61 & --- & --- & --- & --- \\
\hline
\end{tabular}

\section{Conclusions}

According to the design standards, if the edge load is concentrated over a portion of the element length, web local failure needs to be considered. This study focused on relatively stocky webs $(2.8 \leq h / t \leq 28.0)$ that are subjected to web bearing failure. An experimental testing program comprising 34 square and rectangular hollow sections was carried out using four different loading conditions (ETF, ITF, EOF and IOF). 
Finite element models were developed and validated against the test results, after which a parametric study was conducted in order to generate a total of 104 numerical results.

The accuracy of the current design rules for tubular sections against web bearing was investigated. Test and numerical results were compared with the design strengths predicted by the AA, AS/NZS and EC9 for aluminium alloy structures as well as the AISC, the AS4100 and EC3 for steel structures. For the two-flange loading conditions (ETF and ITF), the performances of three aluminium alloy codes (i.e. the AA, the AS/NZS and EC9) are shown to be better than the three steel codes (i.e. the AISC, the AS4100 and EC3).

The combined data of experimental and numerical results were also used to develop a new method for aluminium alloy web bearing design. The format of the proposed design method for the ETF and ITF loading conditions follows similar to the existing design codes but is extended to include the strain hardening effect. The method of calculating the design stress follows the CSM approach. The predictions of the new method have been compared with the experimental results and numerical result. The proposed new design method is found to be accurate and consistent. The scattering of the tested and numerical results-to-predicted ratios for the proposed method were reduced up to $50 \%$ compared to the existing methods. Reliability analyses were conducted and showed that the proposed design rules are safe and reliable. It was 
observed that the bending moment capacity plays a critical role for one-flange loading specimens (EOF and IOF). The interaction of web bearing and bending should be carefully investigated for aluminium alloy stocky tubular sections under IOF loading condition in the future work.

\section{Acknowledgements}

The research work in this paper was supported by a grant from The University of Hong Kong under the seed funding program for basic research. The authors are also grateful

to Mr Wai-Keung Wong for his assistance in the experimental program as part of his final year undergraduate research project at The University of Hong Kong.

\section{Notation}

$\begin{array}{ll}B & =\text { Section width } \\ b & =\text { Flat width of flange } \\ b_{y} & =\text { Length that bearing stresses spread out } \\ E & =\text { Young's modulus } \\ E_{s h} & =\text { Strain hardening modulus } \\ f_{c r} & =\text { Elastic buckling stress } \\ f_{c s m} & =\text { Ultimate tensile strength } \\ f_{u} & =\text { Yield strength, taken as the } 0.2 \% \text { proof strength } \\ f_{y} & =\text { Mean value of fabrication variables } \\ F_{m} & =\text { Section depth } \\ H & \end{array}$




$$
\begin{array}{ll}
h & =\text { Flat depth of web } \\
L & =\text { Member length } \\
l_{e} & =\text { Parameters in formulae for effective loaded length } \\
M_{m} & =\text { Mean value of material factor } \\
m_{l}, m_{2} & =\text { Parameters in formulae for effective loaded length } \\
N & =\text { Length of bearing plate } \\
P_{A A} & =\text { Design strengths from AA } \\
P_{A I S C} & =\text { Design strengths from AISC } \\
P_{A S 4100} & =\text { Design strengths from AS4100 } \\
P_{A S N Z S} & =\text { Design strengths from AS/NZS } \\
P_{E C 3} & =\text { Design strengths from EC3 } \\
P_{E C 9} & =\text { Design strengths from EC9 } \\
P_{e x p} & =\text { Experimental web bearing strength } \\
P_{F E} & =\text { Numerical web bearing strength from finite element analysis } \\
P_{m} & =\text { Mean value of test-to-predicted load ratios } \\
P_{p l} & =\text { Applied loads calculated from the plastic bending moment } \\
P_{p r o p} & =\text { Design strengths from the proposed design method } \\
P_{u} & =\text { Experimental and numerical web bearing strength } \\
V_{P} & =\text { Wall thickness } \\
V_{F} &
\end{array}
$$


$\alpha_{p} \quad=$ Coefficient used to calculate the nominal bearing yield capacity for square and rectangular hollow sections

$\alpha \quad=$ Web crippling coefficient

$\beta \quad=$ Reliability index

$\varepsilon \quad=$ Engineering strain

$\varepsilon_{c s m} \quad=$ CSM limiting strain

$\varepsilon_{\text {true }} \quad=$ Plastic true strain

$\varepsilon_{f} \quad=$ Strain at fracture

$\varepsilon_{u} \quad=$ Strain at the ultimate tensile stress

$\varepsilon_{y} \quad=$ Yield $\operatorname{strain}\left(f_{y} / E\right)$

$k_{F} \quad=$ Buckling factor for transverse force

$\lambda_{F} \quad=$ Slenderness parameter for local buckling due to transverse force

$\bar{\lambda}_{p} \quad=$ Cross-section/plate slenderness

$\sigma \quad=$ Engineering stress

$\sigma_{\text {trure }} \quad=$ True stress

$\chi_{\mathrm{F}} \quad=$ Reduction factor due to local buckling

\section{References}

[1] Young, B. and Hancock, G.J. (2001), "Design of cold-formed channels subjected to web crippling" Journal of Structural Engineering, ASCE 127(10):1137-1144.

[2] Tryland, B. T., Langseth, M., and Hopperstad, O. S. (1999). "Nonperfect aluminum beams subjected to concentrated loading." Journal of Structural Engineering, ASCE 125(8): 900-909. 
[3] Zhou, F. and Young, B. (2008). "Aluminum tubular sections subjected to web crippling-Part I: Tests and finite element analysis." Thin-Walled Structures, 46(4), 339-351.

[4] Zhou, F. and Young, B. (2008). "Aluminum tubular sections subjected to web crippling-Part II: Proposed design equations.” Thin-Walled Structures, 46(4), 352-361.

[5] Zhou, F., Young, B. and Zhao, X. L. (2009), Tests and Design of Aluminum Tubular Sections Subjected to Concentrated Bearing Load", Journal of Structural Engineering, ASCE, 135 (7): 806-817

[6] Macdonald M, Don MAH, Kotelko M, Rhodes J. Web crippling behaviour of thin-walled lipped channel beams. Thin-Walled Struct 2011;49(5):682-90.

[7] Natário P, Silvestre N, Camotim D. Web crippling failure using quasi-static FE models. Thin-Walled Struct 2014;84:34-49.

[8] Hancock GJ, Pham CH. Buckling analysis of thin-walled sections under localised loading using the semi-analytical finite strip method. Thin-Walled Struct 2015;86:35-46.

[9] Gardner, Talja and Baddoo (2006). Structural design of high-strength austenitic stainless steel. Thin-Walled Structures (2006). Vol. 44(5), 517-528.

[10] Zhou F. and Young B. (2006). Cold-formed stainless steel sections subjected to web crippling. Journal of Structural Engineering (2006), ASCE. Vol. 132(1), 134-44.

[11] Zhou F. and Young B. (2007). Cold-formed high-strength stainless steel tubular sections subjected to web crippling. Journal of structural Engineering (2007), ASCE. Vol. 133(3), 368- 377.

[12] Talja A, Salmi P. Design of stainless steel RHS beams, columns and beam columns. Finland: Technical Research Centre of Finland (VTT); 1995

[13] Bock M, Arrayago I, Real E, Mirambell E. Study of web crippling in ferritic stainless steel cold formed sections. Thin-Walled Struct 2013;69:29-44.

[14] Su, M., Young, B. and Gardner, L. (2016). "The continuous strength method for the design of aluminium alloy structural elements", Engineering Structures, 122: 338-348.

[15] Aluminum Association (2015). Aluminum design manual. Washington, DC: The 
Aluminum Association.

[16] AS/NZS (1997) "Aluminium structures - part 1: limit state design, Australian/ New Zealand standard" AS/NZS 1664.1:1997. Sydney, Australia: Standards Australia; 1997.

[17] European Committee for Standardization (EC9). (2007). "EUROCODE 9: Design of aluminum structures-Part 1-1: General rules-General rules and rules for buildings." BS EN 1999-1-1:2007, CEN.

[18] AISC Committee (2010), Specification for Structural Steel Buildings, American Institute of Steel Construction, Chicago, Illinois.

[19] Australian Standards (1998). "Steel structures." AS 4100:1998, Standards Australia, Sydney, Australia.

[20] European Committee for Standardization (EC3). Eurocode 3: design of steel structures - part 1-3: general rules-supplementary rules for cold-formed members and sheeting. EN 1993-1-3. Brussels, Belgium: European committee for standardization (CEN); 2006.

[21] Winter, G., and Pian, R. H. J. (1946), "Crushing strength of thin steel webs." Engineering Experiment Station, Bulletin No. 35, Cornell Univ., Ithaca, N.Y.

[22] Zetlin, L. (1955). "Elastic instability of flat plates subjected to partial edge loads." Journal of Structural Division., 81: 1-24.

[23] Hetrakul, N., and Yu, W. W. (1978). "Structural behaviour of beam webs subjected to web crippling and a combination of web crippling and bending." Civil Engineering Study 78-4, Final Rep., Univ. of Missouri-Rolla, Rolla, Mo.

[24] AISI (2012). North American Specification for the design of cold-formed steel structural members. Washington, DC: American Iron and Steel Institute; 2001.

[25] ABAQUS analysis user's manual (2010) version 6.12. ABAQUS Inc.

[26] AS/NZS (2005). Cold-formed steel structures, Australian/New Zealand standard AS/NZS 4600:2005. Sydney, Australia: Standards Australia.

[27] Australian Standard (AS). (2007). "Methods for tensile testing of metals." AS 1391-2007, Standards Association of Australia, Sydney, Australia.

[28] American Society for Testing and Materials (ASTM). (1997). "Standard test methods for tension testing of metallic materials." E 8M-97, West 
Conshohocken, Pa.

[29] Li, HT and Young B. (2017), "Tests of cold-formed high strength steel tubular sections undergoing web crippling”, Engineering Structures, 141: 571-583.

[30] Ellobody, E. and Young, B. (2005) "Structural performance of cold-formed high strength stainless steel columns", Journal of Constructional Steel Research 61 (12): 1631-1649

[31] Sherbourne, A.N. and Jensen, C.D. (1957), "Direct Welded Beam Column Connections," Report. No. 233.12, Fritz Engineering Laboratory, Lehigh University, Bethlehem, PA.

[32] Graham, J.D., Sherbourne, A.N., Khabbaz, R.N. and Jensen, C.D. (1960), "Welded interior beam-to-column connections," Welding Research Council, Bulletin No. 63, pp. 1-28.

[33] Prochnow, S.D., Ye, Y., Dexter, R.J., Hajjar, J.F. and Cotton, S.C. (2000), “Local Flange Bending and Local Web Yielding Limit States in Steel Moment Resisting Connections," Connections in Steel Structures IV Behavior, Strength and Design, R.T. Leon and W.S. Easterling (eds.), AISC, Chicago, IL, pp. $318-328$.

[34] Hajjar, J.F., Dexter, R.J., Ojard, S.D., Ye, Y. and Cotton, S.C. (2003), "Continuity Plate Detailing for Steel Moment-Resisting Connections," Engineering Journal, AISC, No. 4, 4th Quarter, pp. 81-97

[35] Zhou F. and Young B. (2007). "Experimental Investigation of Cold-Formed High-Strength Stainless Steel Tubular Members Subjected to Combined Bending and Web Crippling”. Journal of structural Engineering, ASCE. 133(37), 1027- 1034.

[36] Su, M., Young, B. and Gardner, L. (2014). "Deformation-based design of aluminium alloy beams", Engineering Structures, 80: 339-349.

[37] Gardner L. The continuous strength method. Proc ICE - Struct Build 2008;161 (3):127-33. 